\title{
Study on Copper Consumption in China and Abroad
}

\author{
Zhang-huang $\mathrm{YE}^{1,2}$, Qiang $\mathrm{YAN}^{2}$ and Jia-huan $\mathrm{GUO}^{3}$ \\ 1.Jiangxi Science and Technology Normal University, Nanchang, Jiangxi; \\ 2.Institute of Mineral Resources, Chinese Academy of Geological Sciences, Beijing; \\ 3.China University of Geosciences, Beijing \\ Corresponding author at chuckverna@sina.com
}

Keywords: Copper consumption, structure, source, comparison

\begin{abstract}
From 2000 to 2010, the consumption of refined copper in China has increased at a speed of 0.49 million tons per year on average, and its cumulative consumption accounted for $65 \%$ of the total consumption since the founding of PRC. In 2013, the copper consumption in China reached 11.81 million tons. The consumption in different sectors are on the rise in terms of absolute amount. Among the consumption sectors, the copper consumption in electricity sector grew at the fastest speed. In terms of per capita consumption, the consumption of refined copper in China was 7.1 kilograms in 2013, and China still has some room for growth. The copper consumption structure in both developing countries and developed countries showed obvious different characteristics at different stages.
\end{abstract}

\section{Introduction}

Copper ore is known as the messenger of human civilization. Bronze is widely used after entering the Bronze Age from the Stone Age, as well as in the modern society. It is concerned that what changes the China copper consumption amount and structures have experienced, how they will change in the future based on the historical data of developed countries.

\section{The Change of Copper Consumption in China}

In the middle period of industrialization, China has a strong demand for mineral resources. Since 2002, China surpassed US in refined copper consumption for the first time, becoming the largest consumer of refined copper around the world. The accumulated consumption of refined copper was 69.30 million tons from 1950 to 2013. From 1950 to 1999, the consumption of refined copper amounted to 23.39 million tons. From 2000 to 2010, the consumption of refined copper reached 43.25 million tons. From 2011 to 2013, the consumption of refined copper arrived at 2.664 million tons (Figure 1).

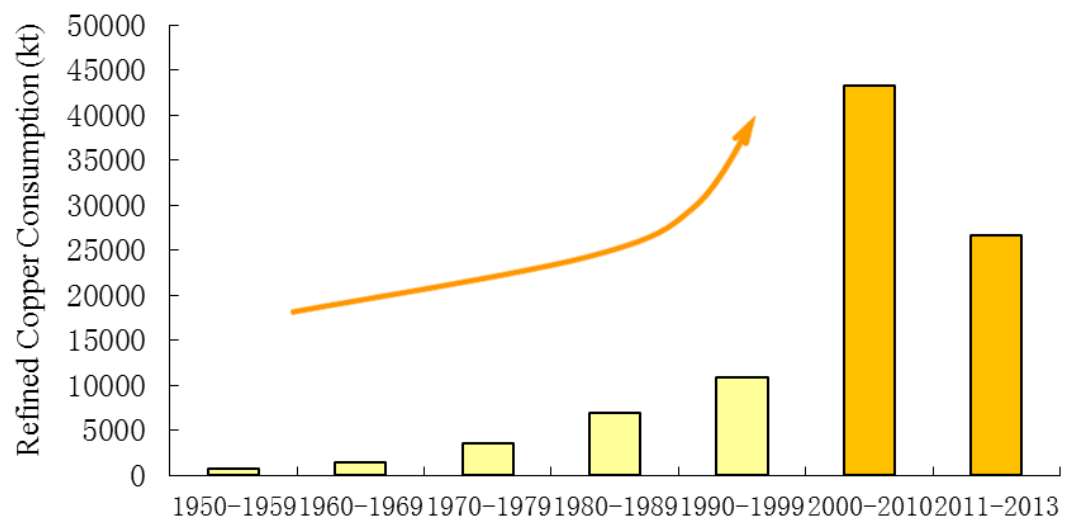

Figure 1 The Consumption of Refined Copper in China Data Source: China Nonferrous Metals Industry Association 
Since the $21^{\text {st }}$ century, the consumption of global refined copper increased from 15.19 million tons in 2000 to 21.039 million tons in 2013. Excluding China's consumption, on the contrary, the consumption of other countries declined from 13.26 million tons in 2000 to 11.26 million tons. It can be seen that China's contribution not only add the major impetus to growth of refined copper consumption, but also offset the reduced part of other countries. In 2013, our imports of refined copper was 3.2 million tons. And imports of refined copper are mainly from Chile, representing one third of total imports; China also imports refined copper from Japan, India, Australia, Kazakhstan, Zambia and South Korea with the proportion being respectively 7.48\%, 7.47\%, 7.35\%, 6.15\%, $4.99 \%$ and $4.58 \%$ of total imports.

\section{The Change of Copper Consumption Structure in China}

In the 1980s, the largest sector of copper consumption in China is electricity with consumption being about $40 \%$; the second largest sector is consumer goods sector with copper consumption being around $20 \%$. And other sectors include machinery manufacturing, transportation, electronic communications and construction sectors. By 2014, the electricity sector still remains to be the largest sector of copper consumption; the proportion of copper consumption in electronic communications and machinery manufacturing grew fast, respectively rising from $5.7 \%$ and $6.7 \%$ in 1990 to $15.1 \%$ and $10.3 \%$ in 2010; while the proportion of copper consumption in transportation and construction sectors grew slowly, respectively increasing from 5.9\% and 3.3\% in 1990 to $7.0 \%$ and $3.7 \%$ in 2010; and the proportion of copper consumption in consumer goods sector was on the decline, decreasing from 20.9\% in 1990 to $15.1 \%$ in 2010 (Figure 2). From the perspective of consumption proportion, the change in every sector is different, but the copper consumption in these sectors are on the rise in terms of absolute amount, among them, the copper consumption in electricity sector grew at the fastest speed.

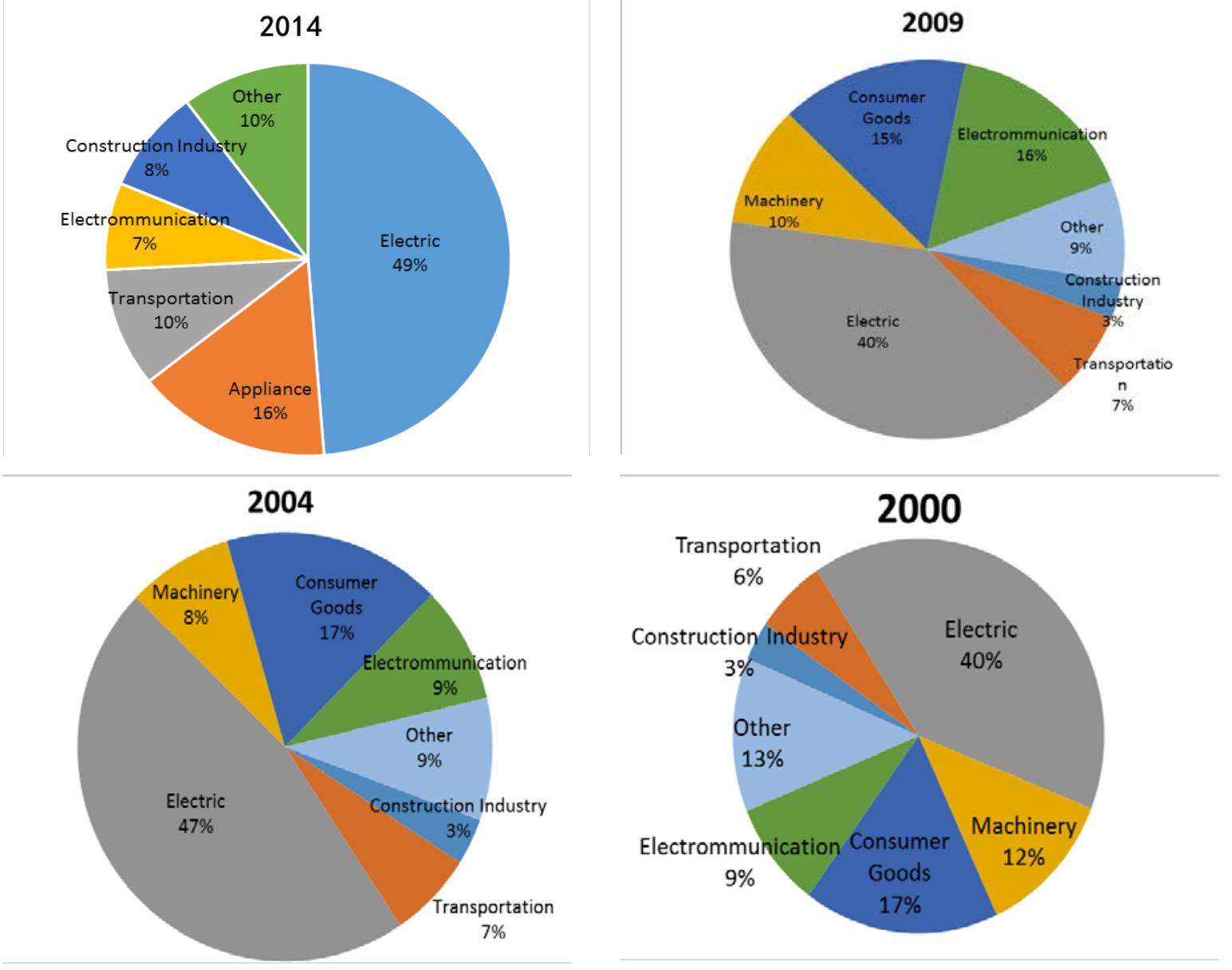

Figure 2 The Contrast of Copper Consumption Structure in China Data Source: China Nonferrous Metals Industry Association 


\section{The Copper Consumption Sources in China}

In 2013, the copper consumption in China reached 11.81 million tons, among them, the home-made copper mine was 1.71 million tons, and the social recovery amounted to 1.98 million tons with the external dependence being $68 \%$. And the consumption of home-made copper mine accounted for $14 \%$ of the total copper consumption, the home-made scrape copper for $17 \%$, imported refined copper for $27 \%$, imported copper mine for $21 \%$, imported scrape copper for $18 \%$ and imported crude copper for 3\% (Figure 3). The consumption of our refined copper was 9.83 million tons in 2013 , occupying $46.7 \%$ of global consumption, ranking the first all over the world.

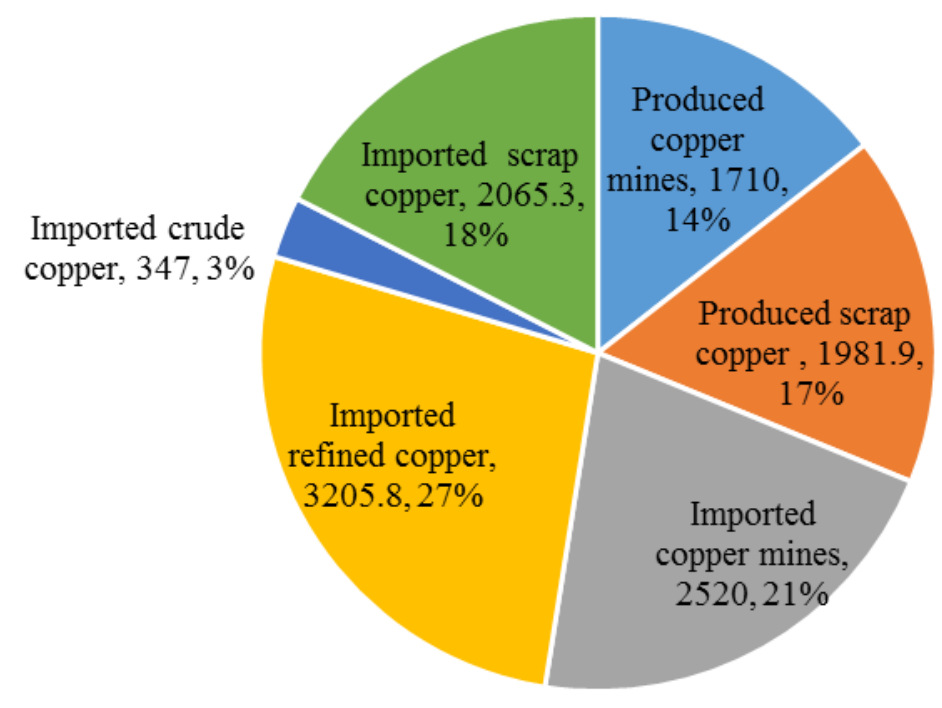

Figure 3 The Copper Consumption sources in China in 2013

Data Source: China Nonferrous Metals Industry Association

\section{The Comparison of Copper Consumption}

\subsection{The Comparison of Per Capita Consumption of Copper}

In 2013, the per capita consumption of refined copper in China was 7.1 kilograms, being nearly 7.8 kilograms in Japan, equivalent to $38 \%$ of that in Taiwan, China and $48 \%$ of that in Korea (Figure 4). 


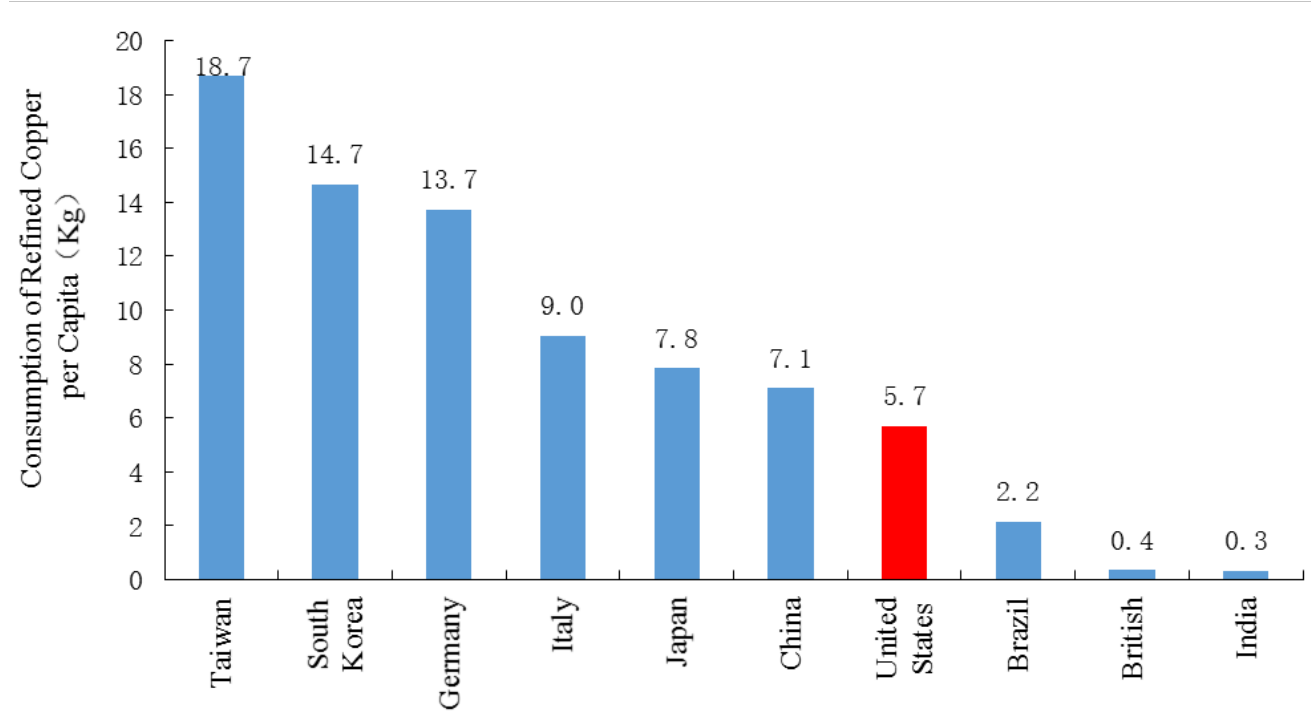

Figure 4 The Per Capita Consumption of Copper in Major Countries and Regions

Data Source: GGDC, WBMS, China Nonferrous Metals Industry Association

Compared with the per capita consumption of refined copper of the same stage of development in developed countries and regions, in 2010, the per capita consumption of refined copper in China corresponded to $62 \%$ of that of US, $67 \%$ of Canada, $81 \%$ of Korea and $84 \%$ of Japan (Figure 5). From 1950 to 2010, the cumulative per capita consumption of refined copper in China was 50 kilograms, 443 kilograms in Japan, 383 kilograms in US, 360 kilograms in Canada and 357 kilograms in Korea. In terms of per capita consumption, China still has some room for growth in copper demand.

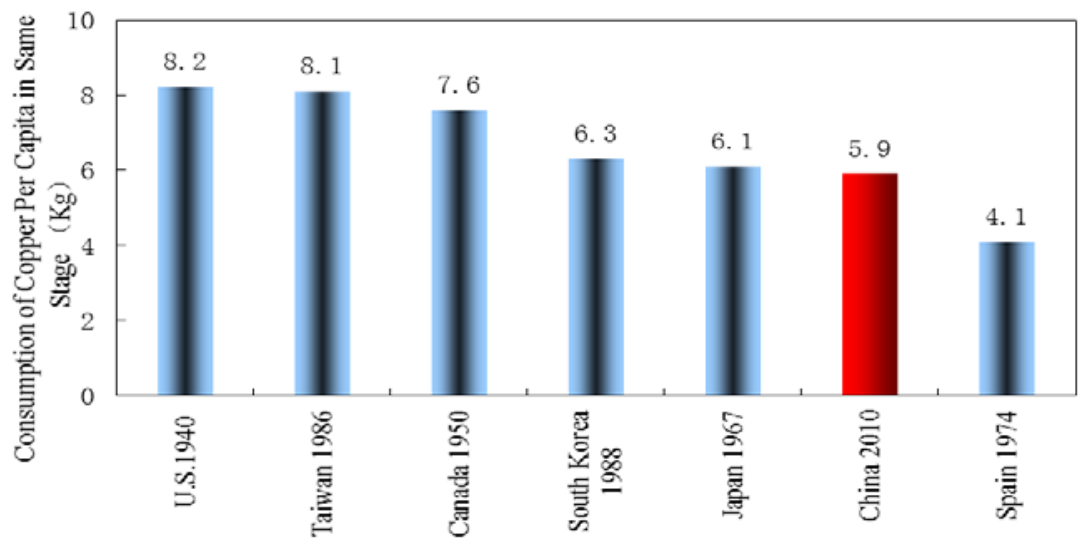

Figure 5 The Per Capita Consumption of the Same Stage of Development in Major Countries and Regions

Data Source: GGDC, WBMS, China Nonferrous Metals Industry Association

\subsection{The Comparison of Copper Consumption Structure}

\subsubsection{Global Copper Consumption Structure}

In 2011, the consumption of global refined copper was 19.47 million tons, and the largest consumer sector was electricity, whose consumption represented $31 \%$ of total copper consumption; the second largest consumer sector was construction, which accounted for $25 \%$ of total copper consumption; the household appliances ranked the third place with consumption being $17 \%$ of total copper consumption; then it is followed by the transportation and machinery manufacturing sectors, whose consumption respectively occupied $12 \%$ and $10 \%$ of total copper consumption(Figure 6 ). But the copper consumption structure in both developing countries and developed countries showed distinguished states. The copper consumption owns obvious characteristics of stage. 
In 2011, the consumption of refined copper in China was 7.33 million tons. And the largest consumer sector was electricity, whose consumption was 3.39 million tons, accounting for $46 \%$ of total refined copper consumption; it is followed by air conditioning refrigeration sector with its consumption being 1.14 million tons, representing $16 \%$ of total refined copper consumption; the copper consumption in transportation sector was 0.77 million tons, representing $11 \%$ of total refined copper consumption; the copper consumption in construction reached 0.68 million tons, being $9 \%$ of total refined copper consumption; the copper consumption in electronic communications arrived at 0.545 million tons, occupying 7\% of total refined copper consumption (Figure 7).

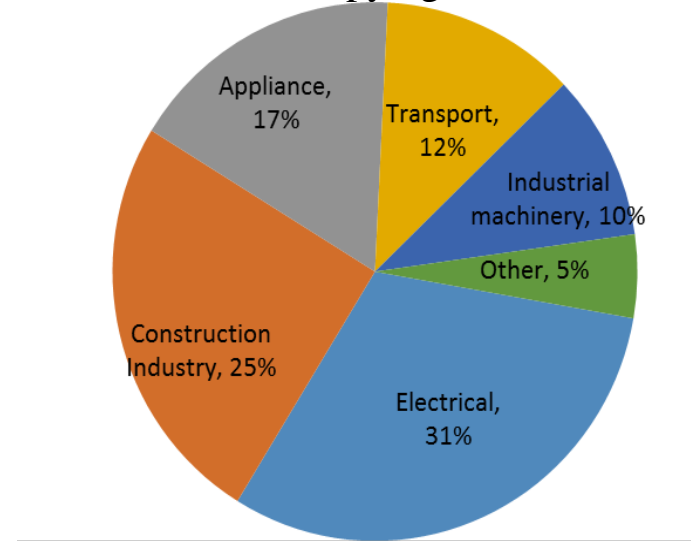

Figure 6 Global Copper Consumption Structure in 2011 Data Source: LME

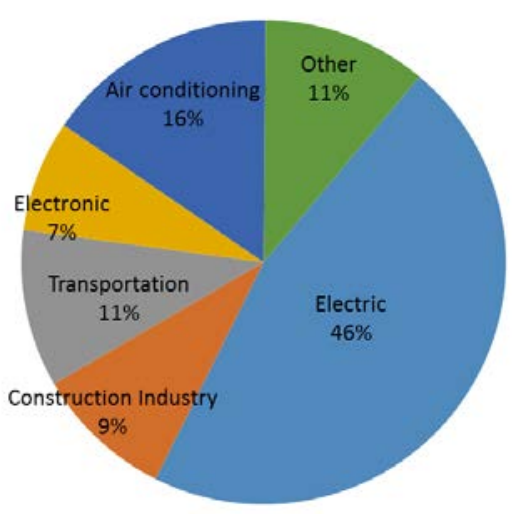

Figure 7 Copper Consumption Structure in China in 2011 Data Source: China Nonferrous Metals Industry Association

\subsubsection{Copper Consumption Structure in US}

In 2010, the largest consumer sector of copper resources was electricity with its consumption occupying $41 \%$ of total copper consumption; electronic communications and household appliances ranked the second place with their consumption respectively representing $15 \%$ of total copper consumption; the third largest sector was machinery manufacturing, whose consumption accounted for $10 \%$ of total copper consumption; then it is followed by transportation and construction sectors with their consumption respectively being $7 \%$ and $4 \%$ of total copper consumption. However, the largest consumer sector of copper resources was construction in 2010, whose consumption represented $49 \%$ of total copper consumption; electronics and electrical sectors were the second largest with their consumption being $20 \%$ of total copper consumption; the third largest sector was transportation, whose consumption accounted for $12 \%$ of total copper consumption; then it is the machinery manufacturing and household appliances, whose consumption occupied respectively $10 \%$ and $9 \%$ of total copper consumption (Figure 8).
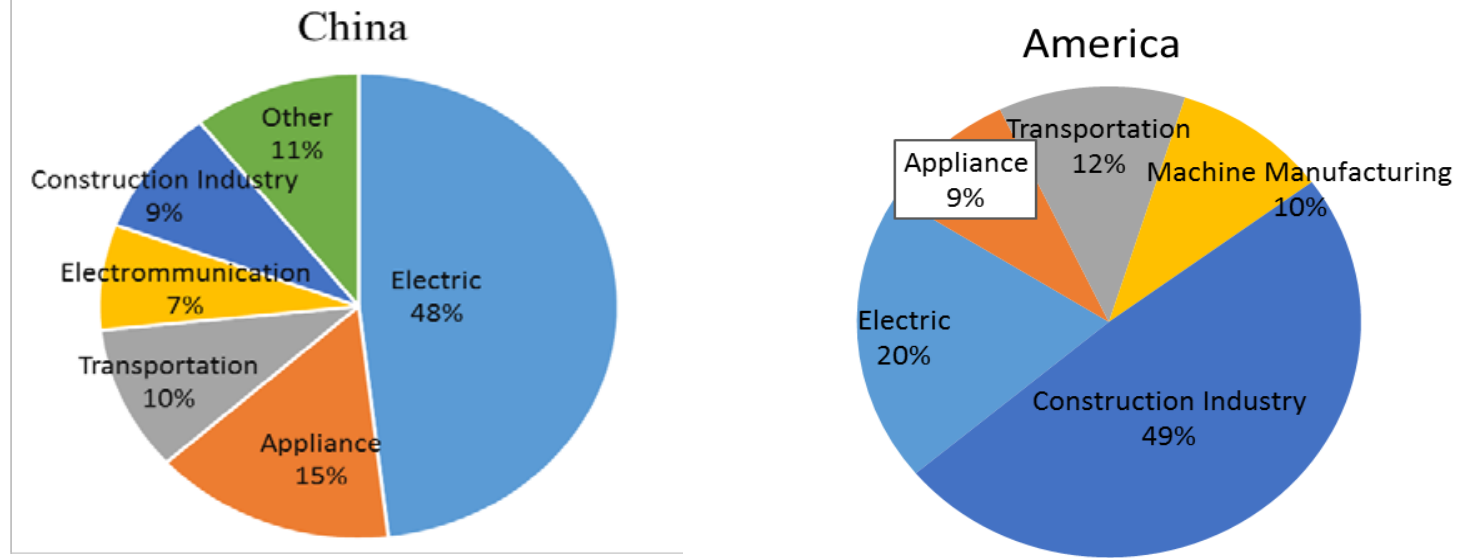

Figure 8 Comparison of Copper Consumption Structure Between China \& US in 2010 Data Source: China Nonferrous Metals Industry Association, USGS 


\section{References}

[1] The statistical bureau of the People's Republic of China, China statistical yearbook, 1980-2014. Beijing: China statistical Publishing House

[2] World Bureau of Metal Statistics, World metal statistics yearbook, 1984-2013. London: World Bureau of Metal Statistics

[3] Copper Development Association Inc, Annual Data 2014, Copper Supply and Consumption 1980-2013. http://www.copper.org/

[4] Wang Anjian, Wang Gaoshang, Zhang Jianhua, etc. 2002. Mineral Resources and National Economy Development [M]. Beijing: Seismological Press

[5] United Nations, Handbook of World Trade Statistics, 1992-2013 